Research Article

\title{
Risk Factors for Vaginal Colonization and Relationship between Bacterial Vaginal Colonization and In-Hospital Outcomes in Women with Obstructed Labor in a Ugandan Regional Referral Hospital
}

\author{
Joseph Ngonzi $\left(\mathbb{D},{ }^{1,2}\right.$ Lisa M. Bebell, ${ }^{3,4}$ Joel Bazira ${ }^{(D)}{ }^{5}$ Yarine Fajardo, ${ }^{1}$ Dan Nyehangane, ${ }^{6}$ \\ Yap Boum $\mathbb{D}^{6},{ }^{6}$ Deborah Nanjebe, ${ }^{6}$ Adeline Boatin, ${ }^{4,7}$ Jerome Kabakyenga, \\ Yves Jacquemyn $\mathbb{D}^{2}{ }^{2}$ Jean-Pierre Van Geertruyden, ${ }^{2}$ and Laura E. Riley ${ }^{7}$ \\ ${ }^{1}$ Mbarara University of Science and Technology, Department of Obstetrics and Gynecology, Mbarara, Uganda \\ ${ }^{2}$ Global Health Institute, University of Antwerp, Antwerp, Belgium \\ ${ }^{3}$ Division of Infectious Diseases, Massachusetts General Hospital, Boston, MA, USA \\ ${ }^{4}$ Massachusetts General Hospital Center for Global Health, Boston, MA, USA \\ ${ }^{5}$ Mbarara University of Science and Technology, Department of Microbiology, Mbarara, Uganda \\ ${ }^{6}$ Epicentre Mbarara Research Base, Mbarara, Uganda \\ ${ }^{7}$ Division of Obstetrics and Gynecology, Massachusetts General Hospital, Boston, MA, USA \\ ${ }^{8}$ Mbarara University of Science and Technology, Institute of Maternal Newborn and Child Health, Mbarara, Uganda \\ Correspondence should be addressed to Joseph Ngonzi; jngonzi@yahoo.com
}

Received 28 April 2018; Revised 31 July 2018; Accepted 2 August 2018; Published 20 September 2018

Academic Editor: Joseph Falkinham

Copyright (c) 2018 Joseph Ngonzi et al. This is an open access article distributed under the Creative Commons Attribution License, which permits unrestricted use, distribution, and reproduction in any medium, provided the original work is properly cited.

\begin{abstract}
Introduction. The proportion of women with severe maternal morbidity from obstructed labor is between 2 and $12 \%$ in resource-limited settings. Maternal vaginal colonization with group B streptococcus (GBS), Escherichia coli, and Enterococcus spp. is associated with maternal and neonatal morbidity. It is unknown if vaginal colonization with these organisms in obstructed labor women is associated with poor outcomes. Objectives. To determine whether vaginal colonization with GBS, E. coli, or Enterococcus is associated with increased morbidity among women with obstructed labor and to determine the risk factors for colonization and antibiotic susceptibility patterns. Methods. We screened all women presenting in labor to Uganda's Mbarara Regional Referral Hospital maternity ward from April to October 2015 for obstructed labor. Those meeting criteria had vaginal swabs collected prior to Cesarean delivery and surgical antibiotic prophylaxis. Swabs were inoculated onto sterile media for routine bacterial culture and antimicrobial susceptibility testing. Results. Overall, 2,168 women were screened and 276 (13\%) women met criteria for obstructed labor. Vaginal swabs were collected from 272 women (99\%), and 170 (64\%) were colonized with a potential pathogen: $49 \%$ with E. coli, 5\% with GBS, and 8\% with Enterococcus. There was no difference in maternal and fetal clinical outcomes between those colonized and not colonized. The number of hours in labor was a significant independent risk factor for vaginal colonization (aOR 1.02, 95\% CI 1.00-1.03, P = 0.04). Overall, 38\% of GBS was resistant to penicillin; $61 \%$ of $E$. coli was resistant to ampicillin, $4 \%$ to gentamicin, and $5 \%$ to ceftriaxone and cefepime. All enterococci were ampicillin and vancomycin susceptible. Conclusion. There was no difference in maternal or neonatal morbidity between women with vaginal colonization with E. coli, GBS, and Enterococcus and those who were not colonized. Duration of labor was associated with increased risk of vaginal colonization in women with obstructed labor.
\end{abstract}




\section{Background}

Obstructed labor is diagnosed in women presenting with features of prolonged or complicated labor, such as labor duration $>24$ hours, distended bladder, Bandl's ring in the lower uterine segment, fetal distress or death, edematous vulva or cervix, fetal caput or significant skull molding, and foul smelling vaginal discharge or amniotic fluid [1]. In resource-limited settings, $2-12 \%$ of women suffer severe obstetric morbidity from obstructed labor. This may include maternal sepsis, uterine rupture, postpartum endometritis, or maternal death, whereas perinatal morbidity may include neonatal sepsis, encephalopathy, or fetal or neonatal demise [2-5].

Several bacterial pathogens such as group B Streptococcus (Streptococcus agalactiae, GBS), Enterococcus spp., and Escherichia coli are known to be associated with poor obstetric and neonatal outcomes, even in women with uncomplicated labor [6-9]. We hypothesized that vaginal colonization with one or more of these known bacterial pathogens (GBS, E. coli, or Enterococcus spp.) is associated with poor maternal and newborn outcomes in women with obstructed labor versus those who are not colonized with those pathogens. We therefore set out to determine risk factors for bacterial vaginal colonization with a potential pathogen and the relationship between colonization and inhospital outcomes among women with obstructed labor.

\section{Methods}

2.1. Study Site and Design. All women presenting to Mbarara Regional Referral Hospital (MRRH) maternity ward for delivery or postpartum care were enrolled in a larger prospective cohort study of postpartum infection at MRRH $[10,11]$ from which a nested substudy of women with obstructed labor were recruited between April and October 2015. MRRH is a teaching hospital for Mbarara University of Science and Technology (MUST) with 10,000 deliveries annually and a catchment of nine million people, who are largely rural dwelling. The proportion of women who were referred to MRRH maternity ward from another clinic or hospital is approximately $15 \%$.

2.2. Definition of Obstructed Labor. For this study, we defined obstructed labor as the presence of two or more major features of obstructed labor (Bandl's ring, edematous vulva, edematous cervix, significant fetal skull molding, or caput), or one major plus one or more minor features of obstructed labor (foul smelling vaginal discharge, fetal distress or demise during labor, $>24$ hours in labor) based on published studies [1, 3]. This definition was applied uniformly to women presenting to MRRH in labor by a single obstetrician to prospectively recruit the subpopulation of women with obstructed labor.

2.3. Participant Enrollment and Data Collection. All women presenting to the MRRH maternity ward for delivery were approached for inclusion. Study procedures for the larger cohort included measurement of vital signs after delivery for all women; symptom questionnaire and chart review for a target subpopulation of women; and a structured physical exam, malaria testing, and blood and urine cultures for febrile and hypothermic women [10]. Among mothers consenting for the larger cohort, those meeting criteria for obstructed labor were consented for additional procedures including vaginal swab collection and structured physical exam. Those $<18$ years of age were enrolled as emancipated minors based on pregnancy status. Potential participants were excluded if they did not understand English or Runyankole (the local dialect) or were incapacitated and their next-of-kin declined participation. All participants provided written informed consent. Participants not previously tested for human immunodeficiency virus (HIV) within the last six months were offered HIV testing and results were recorded, given to the ward clinical care team, and shared with the participant.

After delivery, obstructed labor substudy participants were followed by a team of research nurses who administered a questionnaire which captured their sociodemographic, medical, and obstetric profiles. An abdominal examination was performed on all enrolled women 72 hours after delivery to evaluate for endometritis. Investigatordesigned questionnaire responses and laboratory results were entered into a Research Electronic Data Capture (REDCap) database [12]. The final decision about delivery mode for each participant was made by the obstetric care team without investigator influence, but all enrolled women went on to deliver by Cesarean. Women were followed up at two and six weeks postpartum by phone call and interviewed about their health and the baby's health.

The current routine practice at MRRH for women in labor is to clean the vulva using chlorhexidine prior to digital vaginal examination and to give women undergoing Cesarean delivery a single dose of preoperative antibiotics (usually one gram of intravenous ampicillin) within 30 minutes of skin incision. After Cesarean delivery, women are routinely treated with combination intravenous ceftriaxone, gentamicin, and metronidazole for three days, followed by five days of oral cefixime and oral metronidazole.

2.4. Vaginal Swab Collection. Sterile cotton-tipped swabs were used to collect a midvaginal sample from patients meeting criteria for obstructed labor prior to Cesarean delivery and surgical antibiotic prophylaxis but after vaginal cleansing using chlorhexidine. Swabs were collected in duplicate and delivered to the Epicentre Mbarara Research Centre laboratory for analysis within one hour after collection. The first swab was used to prepare a Gram stain. The second swab was systematically inoculated onto four types of enriched and selective media and incubated at $35-37^{\circ} \mathrm{C}$ in $\sim 5 \%$ carbon dioxide for up to 48 hours, observing for growth after overnight incubation. Bacterial colonies were identified using standard biochemical methods and their identity was confirmed using the analytical profile index system (bioMérieux, Marcy-l'Étoile, France). Antimicrobial susceptibility was determined using 
Kirby-Bauer disk diffusion. Antibiotic breakpoints were defined using European Committee on Antimicrobial Susceptibility Testing (EUCAST) guidelines, version 5.0.

2.5. Outcome Variables. The primary study outcome was postpartum endometritis (puerperal sepsis) at three days postpartum, defined as infection of the female genital tract in which two or more of the following were present: pelvic pain, fever $>38.0^{\circ} \mathrm{C}$, abnormal vaginal discharge, and delay in the rate of reduction of the size of the uterus $<2 \mathrm{~cm} /$ day [5]. The microbiology of puerperal sepsis cases was not evaluated due to the known polymicrobial nature of these infections and local resource constraints. Secondary study outcomes included other maternal outcomes (uterine rupture, postpartum hemorrhage, maternal death, and reoperation) and perinatal outcomes (neonatal Apgar score $<7$, stillbirth, and early neonatal death). The primary exposure variable was vaginal colonization with GBS, E. coli, Enterococcus, or a combination of those pathogens. Secondary exposure variables were as follows: duration of labor, HIV serostatus, duration of rupture of membranes, age, distance of residence from hospital, marital status, educational status, referral status, number of vaginal exams prior to delivery, and parity.

2.6. Sample Size. We calculated the sample size needed to detect a doubling of risk of postpartum endometritis from $10 \%$ to $20 \%$ between women colonized with a potential pathogen and those not colonized as 276 total participants with $80 \%$ power and an alpha error rate of 0.05 .

2.7. Statistical Analysis. We calculated the prevalence of obstructed labor among all laboring women screened, and the proportion of women colonized with a vaginal pathogen, among those with obstructed labor. Demographic characteristics and outcomes were compared between colonized and noncolonized participants using chi-squared or Fisher's exact test for categorical variables and Student's $t$-test or the Wilcoxon rank sum test for continuous variables. $P$ values $<0.05$ were considered statistically significant. A multivariable logistic regression model was used to identify factors associated with vaginal potential pathogen colonization. Variables with a $P$ value $>0.05$ were selected for inclusion in the model which included the following risk factors for vaginal colonization: age, distance of residence from hospital, marital status, educational status, referral status, number of vaginal exams prior to delivery, and parity. All analyses were performed using Stata software (version 12.0, StataCorp, College Station, TX).

2.8. Ethical Clearance. The study and enrollment procedures were approved by the Mbarara University of Science and Technology institutional research committee (08/10-14), Partners Healthcare (2014P002725/MGH), and the Uganda National Council of Science and Technology (HS/1729).

\section{Results}

3.1. Enrollment and Sample Collection. Of 2,168 laboring women consecutively screened between April and October 2015, 276 (13\%) women met criteria for obstructed labor (Figure 1). Of these, 272/276 (99\%) had a vaginal swab collected and $170 / 276(64 \%)$ swabs grew one or more potential pathogens. Of the 170 swabs tested, 157 (92\%) grew one potential pathogen and $13(8 \%)$ grew two potential pathogens (11 with both E. coli and Enterococcus and two with both GBS and E. coli). E. coli was identified in 134 (79\%) of positive vaginal swab cultures, Enterococcus in 22 (13\%), and GBS in 14 (8.2\%), including both samples that grew one potential pathogen and those that grew two pathogens. The overall proportion of E. coli colonization was $49 \%$, Enterococcus was $8 \%$, and GBS was $5 \%$.

\subsection{Participant Characteristics and Exposures by Colonization} Status. There was no significant difference in demographic factors between women having vaginal colonization with a potential pathogen and those not colonized (Table 1), including age $(P=0.97)$, residence in the same municipality as the hospital $(P=0.95)$, marital status $(P=0.09)$, and employment status $(P=0.81)$. There were also no differences in obstetric factors including parity $(P=0.71)$, gestational age $(P=0.13)$, number of vaginal examinations $(P=0.67)$, and antenatal care attendance $(P=0.50)$. The duration of labor was significantly longer in women having vaginal colonization with GBS, E. coli, or Enterococcus compared with those not colonized (median 24 versus 13 hours, $P=0.03$; Table 1 ).

3.3. Maternal and Neonatal Clinical Outcomes. All women enrolled in the study underwent cesarean delivery. Maternal and neonatal outcomes did not differ between women vaginally colonized with a potential pathogen and those not colonized, including endometritis (8 (40\%) versus 6 (55\%), $P=0.44)$, postpartum fever or hypothermia (20 (12\%) versus $11(11 \%), P=0.81)$, death $(1(1 \%)$ versus $0(0), P=0.63)$, postpartum hemorrhage $(1(1 \%)$ versus $1(1 \%), P=0.70)$, stillbirth $(8(5 \%)$ versus $3(3 \%), P=0.50)$, or in-hospital neonatal death $(1(1 \%)$ versus $2(2 \%), P=0.28)$ (Table 2$)$.

3.4. Factors Associated with Colonization. In both univariable and multivariable logistic regression analyses, we controlled for potential confounders including duration of labor, HIV serostatus, age, and number of vaginal exams prior to delivery. After adjusting for potential confounders, number of hours in labor was the only significant independent risk factor for vaginal colonization by a potential pathogen (adjusted odds ratio $(a \mathrm{OR}) 1.02,95 \% \mathrm{CI} 1.00-1.03, P=0.04$; Table 3 ).

3.5. Antimicrobial Susceptibility. Among GBS isolates, 5 (38\%) were resistant to penicillin and among E. coli isolates, $85(61 \%)$ were resistant to ampicillin, $5(4 \%)$ to gentamicin, 6 (4\%) to ciprofloxacin, and $7(5 \%)$ to both ceftriaxone and cefepime (Table 4). No enterococci were resistant to either ampicillin or vancomycin. 


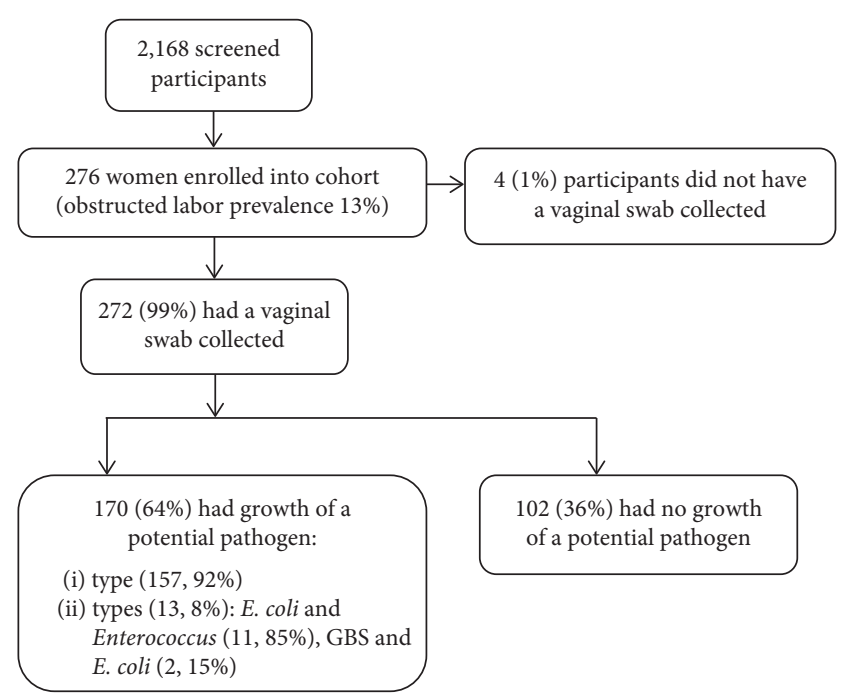

Figure 1: Flowchart of participant enrollment and sample collection.

TABLE 1: Demographic characteristics and obstetric risk factors of obstructed labor participants, comparing women vaginally colonized with a potential pathogen to those not colonized.

\begin{tabular}{|c|c|c|c|}
\hline $\begin{array}{l}\text { Characteristic } \\
(N=272)\end{array}$ & $\begin{array}{l}\text { Colonized, } \\
n=170 \\
(63 \%)\end{array}$ & $\begin{array}{c}\text { Not } \\
\text { colonized, } \\
n=102(37 \%)\end{array}$ & $\begin{array}{c}P \\
\text { value }\end{array}$ \\
\hline Age (years) & & & 0.97 \\
\hline$\leq 19$ & $34(21)$ & $19(21)$ & \\
\hline $20-34$ & $117(75)$ & $68(75)$ & \\
\hline$>34$ & $6(4)$ & $4(4)$ & \\
\hline $\begin{array}{l}\text { Residence in Mbarara } \\
\text { municipality }\end{array}$ & $37(24)$ & $20(24)$ & 0.95 \\
\hline Married & $143(91)$ & $88(97)$ & 0.09 \\
\hline No formal employment & $46(29)$ & $28(31)$ & 0.81 \\
\hline HIV-infected & $10(6)$ & $9(9)$ & 0.36 \\
\hline $\begin{array}{l}\text { Median household monthly } \\
\text { income in UGx (USD) }\end{array}$ & $\begin{array}{c}150,000 \\
(42)\end{array}$ & $100,000(28)$ & 0.10 \\
\hline $\begin{array}{l}\text { Referred to MRRH from } \\
\text { another health facility }\end{array}$ & $62(40)$ & $33(36)$ & 0.57 \\
\hline Attended $\geq 4$ ANC visits & $107(70)$ & $65(72)$ & 0.50 \\
\hline $\begin{array}{l}\text { Received malaria prophylaxis } \\
\text { during pregnancy } \\
\text { (or TMP/SMX prophylaxis } \\
\text { if HIV-infected) }\end{array}$ & $151(96)$ & $88(97)$ & 0.83 \\
\hline $\begin{array}{l}\text { Reported syphilis or sexually } \\
\text { transmitted infection during } \\
\text { pregnancy }\end{array}$ & $0(0)$ & $2(2)$ & \\
\hline Primiparous & $94(60)$ & $50(55)$ & \\
\hline Gestational age at delivery & & & 0.13 \\
\hline Preterm $(<37$ weeks $)$ & $6(4)$ & $7(8)$ & \\
\hline Term (37-42 weeks) & $125(85)$ & $74(87)$ & \\
\hline Postterm (>42 weeks) & $16(11)$ & $4(5)$ & \\
\hline $\begin{array}{l}\text { Reported } \geq 5 \text { vaginal exams } \\
\text { during labor }\end{array}$ & $11(13)$ & $22(15)$ & 0.67 \\
\hline $\begin{array}{l}\text { Estimated duration of labor } \\
\text { in hours, median (IQR) }\end{array}$ & $24(12-43)$ & $13(11-24)$ & 0.03 \\
\hline $\begin{array}{l}\text { Presurgical antibiotic } \\
\text { prophylaxis prescribed }\end{array}$ & $135(87)$ & $80(88)$ & 0.76 \\
\hline
\end{tabular}

UGx: Uganda shilling; USD: United States dollar; MRRH: Mbarara Regional Referral Hospital; ANC: antenatal care; TMP/SMX: trimethoprim/sulfamethoxazole; IQR: interquartile range.
TABLE 2: Maternal and neonatal outcomes of obstructed labor participants, comparing women vaginally colonized with a potential pathogen to those not colonized.

\begin{tabular}{lccc}
\hline Outcome & $\begin{array}{c}\text { Colonized, } \\
n=170(63 \%)\end{array}$ & $\begin{array}{c}\text { Not colonized, } \\
n=102(37 \%)\end{array}$ & $\begin{array}{c}P \\
\text { value }\end{array}$ \\
\hline $\begin{array}{l}\text { Maternal } \\
\quad \text { Endometritis }\end{array}$ & $8(40)$ & $6(55)$ & 0.44 \\
$\begin{array}{l}\text { Postpartum fever } \\
\left(>38.0^{\circ} \mathrm{C}\right) \text { or }\end{array}$ & $20(12)$ & $11(11)$ & 0.81 \\
$\begin{array}{l}\text { hypothermia }\left(<36.0^{\circ} \mathrm{C}\right) \\
\text { Maternal death }\end{array}$ & $1(1)$ & $0(0)$ & 0.63 \\
$\begin{array}{l}\text { Days hospitalized, } \\
\text { mean (SD) }\end{array}$ & $3.4(3)$ & $3.5(3)$ & 0.83 \\
$\begin{array}{l}\text { Reoperation } \\
\text { Postpartum urinary }\end{array}$ & $1(1)$ & 0 & 0.45 \\
tract infection & $1(5)$ & $1(10)$ & 0.61 \\
$\begin{array}{l}\text { Postpartum } \\
\text { hemorrhage }\end{array}$ & $1(1)$ & $1(1)$ & 0.70 \\
$\begin{array}{l}\text { Readmission to } \\
\text { MRRH within } 6 \text { weeks } \\
\text { postpartum }\end{array}$ & $2(1)$ & $2(2)$ & 0.60 \\
\hline $\begin{array}{l}\text { Neonatal } \\
\text { Live birth }\end{array}$ & $156(100)$ & $91(99)$ & 0.19 \\
$\begin{array}{l}\text { Stillbirth } \\
\text { In-hospital } \\
\text { neonatal death }\end{array}$ & $8(5)$ & $3(3)$ & 0.51 \\
$\begin{array}{l}\text { 1-minute Apgar }<7 \\
\text { 5-minute Apgar }<7\end{array}$ & $11(1)$ & $2(2)$ & 0.28 \\
\hline
\end{tabular}

SD: standard deviation; MRRH: Mbarara Regional Referral Hospital.

TABLE 3: Univariable and multivariable logistic regression analysis of factors associated with vaginal colonization by a bacterial pathogen.

\begin{tabular}{|c|c|c|c|c|}
\hline \multirow[b]{2}{*}{ Characteristic } & \multicolumn{2}{|c|}{ Univariable } & \multicolumn{2}{|c|}{ Multivariable } \\
\hline & $\begin{array}{c}\mathrm{cOR} \\
(95 \% \mathrm{CI})\end{array}$ & $\begin{array}{c}P \\
\text { value* }^{*}\end{array}$ & $\begin{array}{c}\mathrm{aOR} \\
(95 \% \mathrm{CI})\end{array}$ & $\begin{array}{c}P \\
\text { value* }^{*}\end{array}$ \\
\hline $\begin{array}{l}\text { Number of hours } \\
\text { in labor }\end{array}$ & $\begin{array}{c}1.02 \\
(1.00-1.03)\end{array}$ & 0.03 & $\begin{array}{c}1.02 \\
(1.00-1.03)\end{array}$ & 0.04 \\
\hline $\begin{array}{l}\text { Number of vaginal } \\
\text { exams in labor }\end{array}$ & $\begin{array}{c}0.97 \\
(0.87-1.08)\end{array}$ & 0.58 & $\begin{array}{c}0.95 \\
(0.84-1.07)\end{array}$ & 0.40 \\
\hline Multiparous & $\begin{array}{c}0.89 \\
(0.60-1.32)\end{array}$ & 0.58 & $\begin{array}{c}0.9 \\
(0.41-8.95)\end{array}$ & 0.41 \\
\hline Formally employed & $\begin{array}{c}0.93 \\
(0.53-1.64)\end{array}$ & 0.81 & $\begin{array}{c}0.77 \\
(0.40-1.09)\end{array}$ & 0.43 \\
\hline HIV-infected & $\begin{array}{c}0.65 \\
(0.25-1.65)\end{array}$ & 0.36 & $\begin{array}{c}0.88 \\
(0.28-2.76)\end{array}$ & 0.83 \\
\hline Age (year & $\begin{array}{c}0.99 \\
(0.94-1.04)\end{array}$ & 0.59 & $\begin{array}{c}1.0 \\
(0.92-1.09)\end{array}$ & 0.99 \\
\hline $\begin{array}{l}\text { Residence in Mbarara } \\
\text { district }\end{array}$ & $\begin{array}{c}0.98 \\
(0.52-1.83)\end{array}$ & 0.95 & $\begin{array}{c}1.0 \\
(0.51-2.00)\end{array}$ & 1.0 \\
\hline
\end{tabular}

HIV: human immunodeficiency virus; CI: confidence intervals; OR: odds ratio; cOR: crude odds ratio; aOR: adjusted odds ratio. ${ }^{*}$ Tests of association between cohort characteristics and the presence or absence of vaginal colonization were performed using univariable or multivariable logistic regression analysis.

\section{Discussion}

The prevalence of obstructed labor in our study was 13\%, similar to what has been reported in other resource-limited settings including Ethiopia (11\%) and southwestern Uganda 
TABLE 4: Proportion of potential vaginal pathogens testing resistant or intermediate susceptibility to selected antimicrobials.

\begin{tabular}{|c|c|c|c|c|c|c|c|c|c|c|}
\hline$N$ & Pen $(n, \%)$ & $\operatorname{Amp}(n, \%)$ & $\operatorname{Ctx}(n, \%)$ & $\operatorname{Cef}(n, \%)$ & Gent $(n, \%)$ & $\operatorname{Ery}(n, \%)$ & $\begin{array}{c}\text { TMP/SMX } \\
(n, \%)\end{array}$ & Tet $(n, \%)$ & $\operatorname{Van}(n, \%)$ & $\operatorname{Cip}(n, \%)$ \\
\hline GBS $(n=14)$ & $5 / 14(38)$ & - & - & - & - & $3 / 14(21)$ & $12 / 14(92)$ & $\begin{array}{c}12 / 14 \\
(92)\end{array}$ & - & - \\
\hline $\begin{array}{l}\text { E. coli } \\
(n=139)\end{array}$ & - & $85 / 139(61)$ & $7 / 139(5)$ & $7 / 139(5)$ & $5 / 139(4)$ & - & $\begin{array}{c}104 / 139 \\
(75)\end{array}$ & - & - & $6 / 136(4)$ \\
\hline $\begin{array}{l}\text { Enterococcus } \\
(n=56)\end{array}$ & - & $0 / 29(0)$ & - & - & $0 / 56(0)$ & - & - & - & $0 / 49(0)$ & - \\
\hline
\end{tabular}

Pen: penicillin; Amp: ampicillin; Ctx: ceftriaxone; Cef: cefepime; Gent: gentamicin; Ery: erythromycin; TMP/SMX: trimethoprim/sulfamethoxazole; Tet: tetracycline; Van: vancomycin; Cip: ciprofloxacin.

$(8 \%)[13,14]$. Contrary to our hypothesis, we found no significant difference in adverse maternal or neonatal outcomes between women with obstructed labor who had vaginal colonization with E. coli, GBS, or enterococci compared with those not colonized. Our primary outcome, postpartum endometritis, occurred in $8(40 \%)$ in the colonized women and 6 (55\%) among the noncolonized group $(P=0.44)$.

Our primary finding of no difference in clinical outcomes between women colonized and those not colonized with a potential pathogen may reflect a number of factors. Since it is standard practice at MRRH for women in labor to have vaginal cleansing with chlorhexidine before any pelvic procedure is done, potential pathogens present in the vaginal canal may have been reduced or eliminated by chlorhexidine, preventing adverse outcomes in these women. Chlorhexidine has activity against vaginal bacteria, which causes puerperal infection, including GBS, E. coli, and enterococci [15]. The small overall number of adverse maternal outcomes (14 (5\%) developed endometritis) and fetal outcomes (13 (5\%) stillbirths) would have also contributed to the finding of no significant difference in the outcomes between the two groups. The small numbers also led our study to be underpowered, reducing our ability to detect a difference in outcomes between the two groups. Because prior studies have focused on infections caused by these potential pathogens [16-18] and not specifically on asymptomatic colonization, it is difficult to compare our finding of a lack of association between vaginal colonization and outcomes with prior studies. It is also possible that previous research demonstrating increased risk of poor outcomes among women with GBS, E. coli, and Enterococcus infections may reflect colonization with particularly virulent strains of these bacteria, and we did not measure pathogen virulence in our study. However, among women colonized with potentially pathogenic bacteria, we presume that virulent strains are more likely to be associated with clinical infection than less virulent colonizers and may account for differences in infectious outcomes between studies. It is also possible that the three pathogens selected for this study may not be the most important pathogens causing adverse pregnancy outcomes, or that a combination of pathogens or the total microbial load and environment of the vagina is a more important determinant of outcomes. These are potential areas for future research.

Our description of the microbiology and antimicrobial susceptibility of three important bacteria among a high-risk population of laboring women may be useful to determine empiric antibiotic treatment for women with obstructed labor who develop peripartum infections in resource-limited settings. We found that the proportion of $E$. coli vaginal colonization during obstructed labor was $49 \%$, higher than $13-23 \%$ reported colonization in other populations of nonobstructed laboring women [19-22]. Higher E. coli colonization rates may reflect an increased number of vaginal exams during labor or increasing vaginal contamination by anorectal bacteria as a result of prolonged or obstructed labor. Because maternal vaginal bacterial colonization with $E$. coli is associated with early onset neonatal sepsis, postpartum endometritis, urinary tract infections, and chorioamnionitis [8,23], E. coli antibiotic susceptibility patterns have important implications for empiric antibiotic selection. In resource-limited settings, common empiric antibiotics for neonatal sepsis, endometritis, urinary tract infection, and chorioamnionitis often include ampicillin, gentamicin, ceftriaxone, ciprofloxacin, or some combination of these first-line antibiotics. We found that $61 \%$ of $E$. coli vaginal isolates were resistant to ampicillin, similar to what has been described elsewhere [21, 24]. We found low-level resistance for $E$. coli to ceftriaxone, gentamicin, and ciprofloxacin, which is reassuring that one or more of these commonly used empiric antibiotic choices are likely to be effective against $E$. coli infections in this setting.

We found a low prevalence (5\%) of vaginal GBS colonization in our study population, lower than estimates from other resource-limited settings, ranging from 8 to $31 \%$ [25-27], including a prior study at MRRH among pregnant nonlaboring women which demonstrated $29 \%$ combined vaginal/rectal GBS colonization [26]. A five percent (5\%) prevalence of vaginal GBS colonization is surprisingly low for this setting, especially as all vaginal swabs were collected prior to cleaning the vulva with chlorhexidine and prior to giving prophylactic antibiotics for Cesarean delivery. The low GBS prevalence could be partially explained by antibiotic use prior to hospital arrival or vaginal cleaning at home prior to admission, though presumably this would have also affected women in the previous MRRH cohort that found a higher GBS prevalence. We collected samples from the vagina only, not the rectum, which may also partially explain our low GBS colonization prevalence. Lastly, women in our study were enrolled in advanced labor, which differs from prior studies done during 2 nd and 3 rd trimester, but not during labor. Current local practice does not include 
screening or treatment of vaginal GBS colonization during pregnancy. Compared with a prior study finding $0 \%$ resistance to penicillin among vaginal GBS isolates [28], we found $38 \%$ resistance of GBS to penicillin. It is difficult to interpret the significance of these results, given the small number of isolates in our study.

Lastly, we found $8 \%$ vaginal enterococcus colonization in our study, the same proportion as in another study in pregnant women [9]. All enterococci isolated in our study were susceptible to both ampicillin and vancomycin, suggesting that postpartum enterococcal infections would likely be well treated by commonly used empiric antibiotic regimens, which usually include ampicillin.

There are several strengths to our study, including its prospective design and collection of vaginal swabs from nearly all (99\%) participants with obstructed labor. Some weaknesses of the study include incomplete chart documentation which could have affected the outcome information abstracted from charts. Though research assistants carefully examined participants' charts for these outcome informations, they were only able to abstract what was recorded by the clinical team. Information about perisurgical antibiotic receipt in the hospital charts was also incomplete. In addition, we followed women physically only until hospital discharge, completing the two-week and sixweek follow-up questionnaires by phone. Infections developing after discharge would not have been captured in our results and could be an important source of postpartum morbidity among women with obstructed labor. Lastly, we only performed one exam at three days postpartum to diagnose endometritis among study participants. For this reason, women developing endometritis more than three days postpartum but prior to hospital discharge would also have been missed.

\section{Conclusions}

We found no difference in maternal and neonatal clinical outcomes among women with obstructed labor between those who had vaginal colonization with a potential pathogen and those not colonized. Increased duration of labor was associated with increased risk of vaginal colonization, and the microbiology of vaginal swabs was dominated by Gram-negative rods. Increasing availability of microbiology testing to inform appropriate antibiotic use and determine the composition of vaginal flora around the time of delivery in patients with obstructed labor, and strengthening antimicrobial stewardship programs should be prioritized.

\section{Data Availability}

The STATA data used to support the findings of this study are available from the corresponding author upon request.

\section{Ethical Approval}

Ethical review and clearance was obtained from Mbarara University Research Ethical Committee (08/10-14), Uganda
National Council and Technology (HS/1729), and Partners Healthcare (2014P002725/MGH).

\section{Consent}

The participants gave informed written consent to participate in the study.

\section{Disclosure}

The funding bodies had no role in the design of the study; collection, analysis, and interpretation of data; or writing the manuscript.

\section{Conflicts of Interest}

The authors declare that there are no conflicts of interest.

\section{Acknowledgments}

The authors extend great gratitude to all study participants, study staff, and staff of the Epicentre Mbarara Research Centre, MGH Center for Global Health, International Health Unit at the University of Antwerp, Mbarara Regional Referral Hospital and Maternity Ward staff, and Mbarara University of Science and Technology for their partnership in this research. JN was supported by both Moms Helping Moms Program, a philanthropic fund created at $\mathrm{MGH}$ and VLIR-UOS via the HEFS Platform Harvest Call (ZIUS2013VOA0902). LMB was supported by NIH Research Training Grant no. R25 TW009337 (FIC/NIMH) and NIH T32 \#5T32AI007433-22, with travel support from the MGH Center for Global Health KL2/Catalyst Medical Research Investigator Training Award (an appointed KL2 award) from Harvard Catalyst, the Harvard Clinical and Translational Science Center (National Center for Advancing Translational Sciences, National Institutes of Health Award KL2 TR001100) and the Charles H. Hood Foundation. YJ and JPVg were supported partly by VLIR-UOS via the HEFS Platform Harvest Call (ZIUS2013VOA0902).

\section{References}

[1] W. Abraham and Y. Berhan, "Predictors of labor abnormalities in University hospital: unmatched case control study," BMC Pregnancy and Childbirth, vol. 14, no. 1, p. 256, 2014.

[2] A. Prual, M.-H. Bouvier-Colle, L. D. Bernis, and G. Breart, "Severe maternal morbidity from direct obstetric causes in West Africa: incidence and case fatality rates," Bulletin of the World Health Organization, vol. 78, no. 5, pp. 593-602, 2000.

[3] S. Fantu, H. Segni, and F. Alemseged, "Incidence, causes and outcome of obstructed labor in Jimma University specialized hospital," Ethiopian Journal of Health Sciences, vol. 20, no. 3, pp. 145-159, 2010.

[4] C. T. Rael, A. Carballo-Dieguez, R. Norton et al., "Identifying strategies to cope with hiv-related stigma in a group of women living with HIV/AIDS in the dominican republic: a qualitative study," AIDS and Behavior, vol. 21, no. 9, pp. 2589-2599, 2016. 
[5] C. Dolea and C. Stein, Global Burden of Maternal Sepsis in the Year 2000, World Health Organization, Geneva, ON, USA, 2003.

[6] M. Obata-Yasuoka, W. Ba-Thein, T. Tsukamoto, H. Yoshikawa, and H. Hayashi, "Vaginal Escherichia coli share common virulence factor profiles, serotypes and phylogeny with other extraintestinal E. coli," Microbiology, vol. 148, no. 9, pp. 2745-2752, 2002.

[7] C. P. Hornik, P. Fort, R. H. Clark et al., "Early and late onset sepsis in very-low-birth-weight infants from a large group of neonatal intensive care units," Early Human Development, vol. 88, no. 2, pp. S69-S74, 2012.

[8] T. C. Dechen, K. Sumit, and P. Ranabir, "Correlates of vaginal colonization with group B streptococci among pregnant women," Journal of Global Infectious Diseases, vol. 2, no. 3, pp. 236-241, 2010.

[9] E. Ghasemi, S. Mansouri, and N. Shahabinejad, "Vaginal colonization and susceptibility to antibiotics of enterococci during late pregnancy in Kerman City, Iran," Archives of Clinical Infectious Diseases, vol. 11, no. 4, 2016.

[10] L. M. Bebell, J. Ngonzi, J. Bazira et al., "Antimicrobialresistant infections among postpartum women at a Ugandan referral hospital," PLoS One, vol. 12, no. 4, Article ID e0175456, 2017

[11] L. M. Bebell, J. Ngonzi, M. J. Siedner et al., "HIV Infection and risk of postpartum infection, complications and mortality in rural Uganda," AIDS Care, vol. 30, no. 8, pp. 943-953, 2018.

[12] P. A. Harris, R. Taylor, R. Thielke, J. Payne, N. Gonzalez, and J. G. Conde, "Research electronic data capture (REDCap)--a metadata-driven methodology and workflow process for providing translational research informatics support," Journal of Biomedical Informatics, vol. 42, no. 2, pp. 377-381, 2009.

[13] A. Henok and A. Asefa, "Prevalence of obstructed labor among mothers delivered in Mizan-Aman general hospital, South West Ethiopia: a retrospective study," Journal of Womens Health Care, vol. 4, no. 5, 2015.

[14] J. K. Kabakyenga, P. O. Ostergren, E. Turyakira, P. K. Mukasa, and K. O. Pettersson, "Individual and health facility factors and the risk for obstructed labour and its adverse outcomes in south-western Uganda," BMC Pregnancy Childbirth, vol. 11, no. 1, p. 73, 2011.

[15] C. Bell, L. Hughes, T. Akister, V. Ramkhelawon, A. Wilson, and D. Lissauer, "What is the result of vaginal cleansing with chlorhexidine during labour on maternal and neonatal infections? a systematic review of randomised trials with metaanalysis," BMC Pregnancy and Childbirth, vol. 18, no. 1, p. 139, 2018.

[16] B. J. Stoll, N. I. Hansen, P. J. Sánchez et al., "Early onset neonatal sepsis: the burden of group B streptococcal and E. coli disease continues," Pediatrics, vol. 127, no. 5, pp. 817-826, 2011.

[17] E. J. Weston, T. Pondo, M. M. Lewis et al., "The Burden of invasive early-onset neonatal sepsis in the United States, 2005-2008," The Pediatric Infectious Disease Journal, vol. 30, no. 11, pp. 937-941, 2011.

[18] S. J. Schrag, J. L. Hadler, K. E. Arnold, P. Martell-Cleary, A. Reingold, and A. Schuchat, "Risk factors for invasive, earlyonset Escherichia coli infections in the era of widespread intrapartum antibiotic use," Pediatrics, vol. 118, no. 2, pp. 570-576, 2006.

[19] M. Mobasheri, N. S. Varnamkhast, A. Karimi, and S. Banaeiyan, "Prevalence study of genital tract infections in pregnant women referred to health centers in Iran," Turkish Journal of Medical Sciences, vol. 44, no. 2, pp. 232-236, 2014.
[20] T. K. Sangeetha, S. Golia, and C. L. Vasudha, "Study of aerobic bacterial pathogens associated with vaginitis in reproductive age group women (15-45 years) and their sensitivity pattern," International Journal of Research in Medical Sciences, vol. 3, no. 9, pp. 232-236, 2015.

[21] E. Sáez-López, E. Guiral, D. Fernández-Orth et al., "Vaginal versus obstetric infection Escherichia coli isolates among pregnant women: antimicrobial resistance and genetic virulence profile," PloS One, vol. 11, no. 1, Article ID e0146531, 2016.

[22] S. D. Karou, F. Djigma, T. Sagna et al., "Antimicrobial resistance of abnormal vaginal discharges microorganisms in Ouagadougou, Burkina Faso," Asian Pacific Journal of Tropical Biomedicine, vol. 2, no. 4, pp. 294-297, 2012.

[23] G. J. Chan, A. H. Baqui, J. K. Modak et al., "Early-onset neonatal sepsis in Dhaka, Bangladesh: risk associated with maternal bacterial colonisation and chorioamnionitis," Tropical Medicine and International Health, vol. 18, no. 9, pp. 1057-1064, 2013.

[24] B. J. Stoll, N. Hansen, A. A. Fanaroff et al., "Changes in pathogens causing early-onset sepsis in very-low-birth-weight infants," New England Journal of Medicine, vol. 347, no. 4, pp. 240-247, 2012.

[25] E. Barcaite, A. Bartusevicius, R. Tameliene, L. Maleckiene, A. Vitkauskiene, and R. Nadisauskiene, "Group B streptococcus and Escherichia coli colonization in pregnant women and neonates in Lithuania," International Journal of Gynecology and Obstetrics, vol. 117, no. 1, pp. 69-73, 2012.

[26] A. Namugongo, J. Bazira, Y. Fajardot, and N. Joseph, "Group B streptococcus colonization among pregnant women attending antenatal care at tertiary hospital in rural Southwestern Uganda," International Journal of Microbiology, vol. 2016, pp. 1-7, 2016.

[27] G. Chan, J. Modak, A. Mahmud, A. Baqui, R. Black, and S. Saha, "Maternal and neonatal colonization in Bangladesh: prevalences, etiologies and risk factors," Journal of Perinatology, vol. 33, no. 12, pp. 971-976, 2013.

[28] J. Y. Bolukaoto, C. M. Monyama, M. O. Chukwu et al., "Antibiotic resistance of Streptococcus agalactiae isolated from pregnant women in Garankuwa, South Africa," BMC Research Notes, vol. 8, no. 1, p. 364, 2015. 


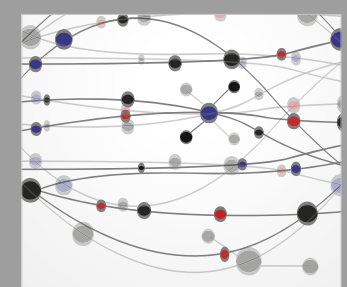

The Scientific World Journal
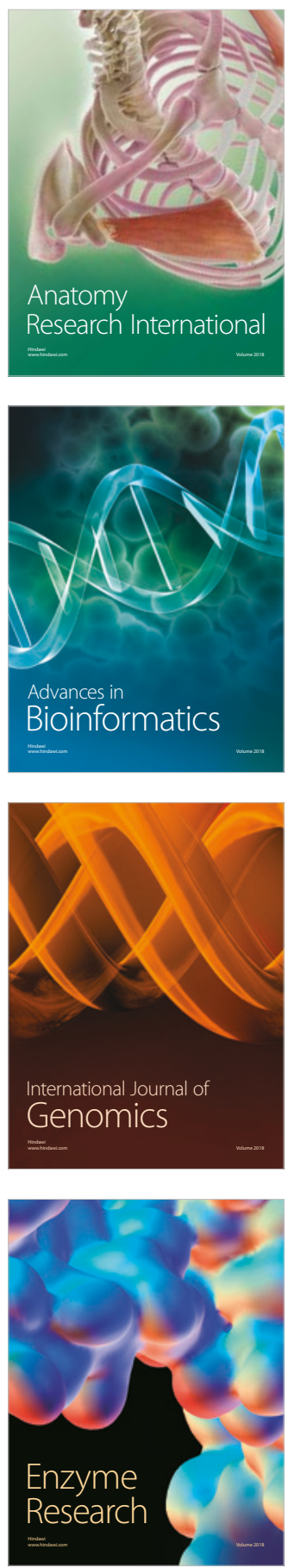
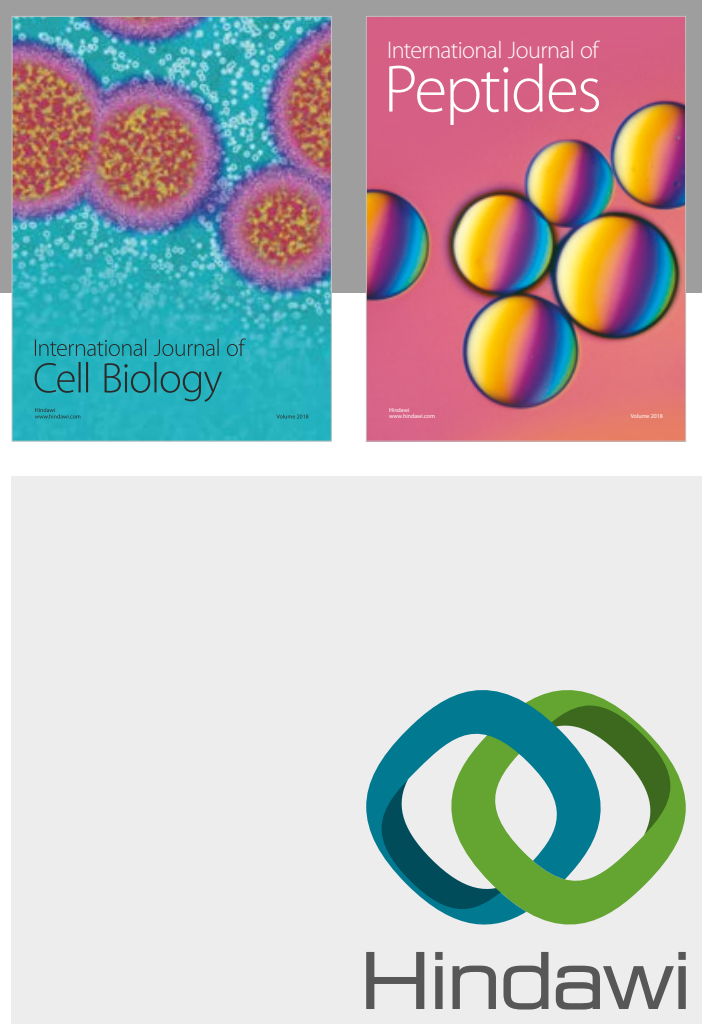

Submit your manuscripts at

www.hindawi.com
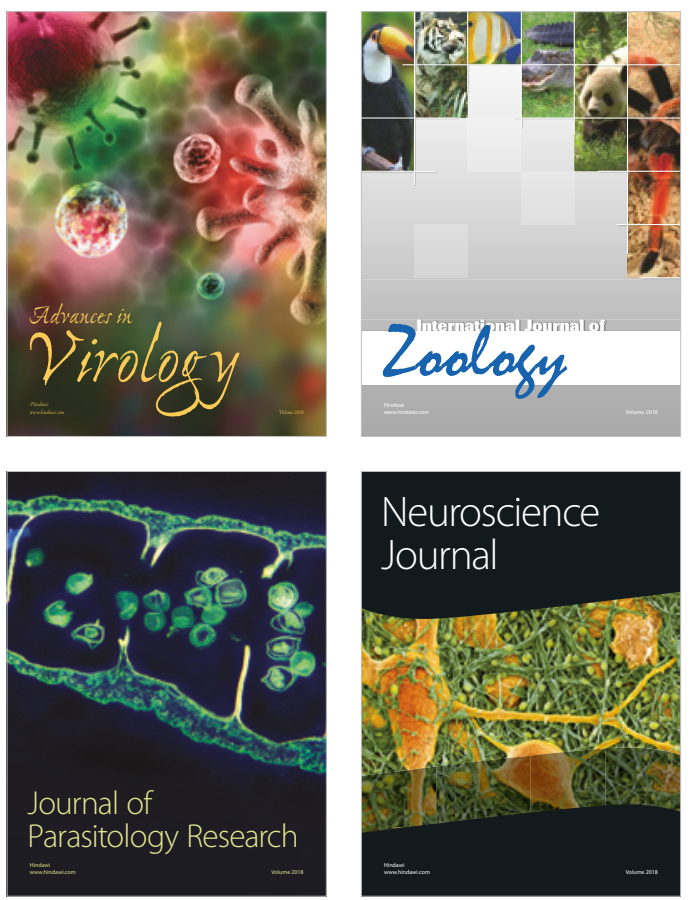
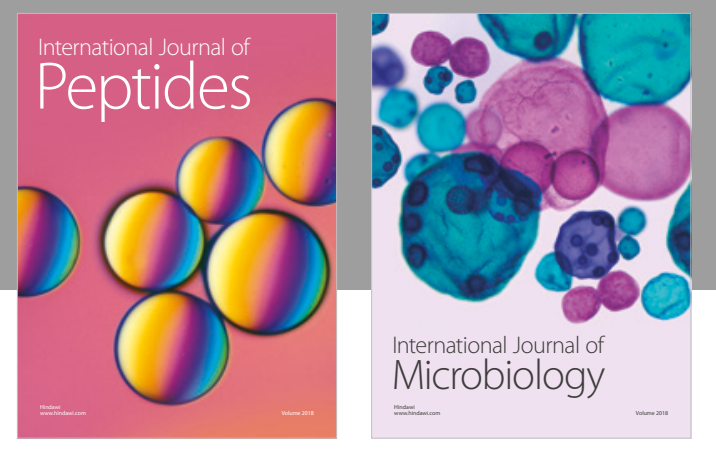

nternational Journal of Microbiology
Journal of
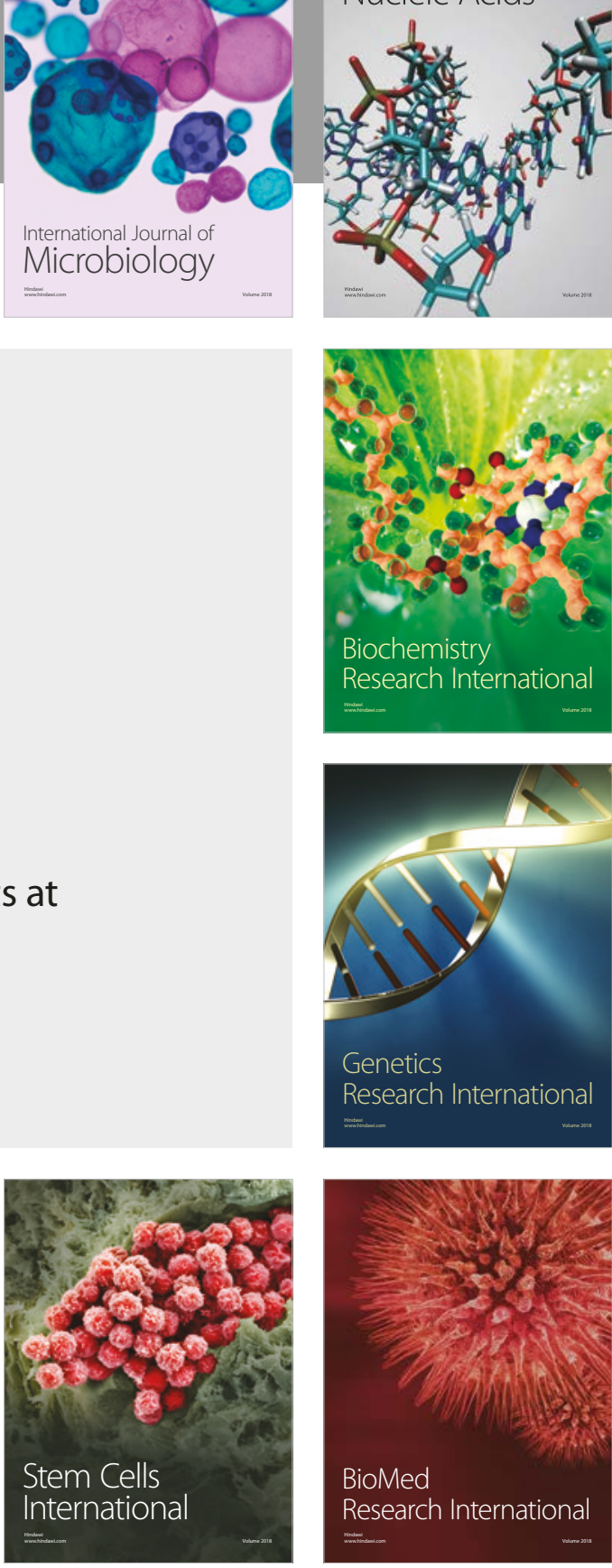
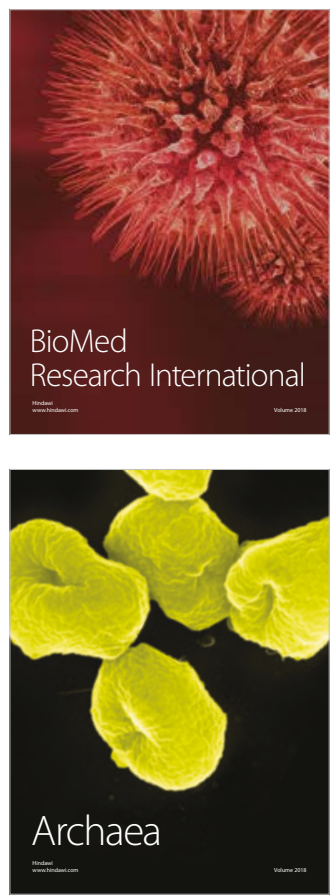